\title{
VARIAÇÕES DO FOCO NARRATIVO EM EL MUNDO ALUCINANTE ${ }^{1}$
}

\section{VARIATIONS OF NARRATIVE FOCUS IN EL MUNDO ALUCINANTE}

\author{
Altamir Botoso ${ }^{2}$
}

\begin{abstract}
RESUMO: A proposta deste artigo é estudar os narradores do romance El mundo alucinante (1966), do escritor cubano Reinaldo Arenas (1943-1990). Tais narradores são um dos recursos empregados por Arenas para valorizar e reavaliar a atuação do frei José Servando Teresa de Mier Noriega y Guerra (1763-1827) na ficção, uma vez que ele foi quase completamente ignorado pelo discurso historiográfico.
\end{abstract}

PALAVRAS-CHAVE: Reinaldo Arenas; Literatura Cubana; Romance histórico; Narrador; El mundo alucinante.

ABSTRACT: The purpose of this article is to study the narrators of the novel El mundo alucinante (1966), by the Cuban writer Reinaldo Arenas (1943-1990). Such narrators are one of the resources used by Arenas to valorize and re-evaluate friar José Servando Teresa de Mier Noriega y Guerra (1763-1827)'s performance in fiction, because he was almost overlooked by historiography discourse.

KEYWORDS: Reinaldo Arenas; Cuban literature; Historical novel; Narrator; El mundo alucinante.

O romance El mundo alucinante, de Reinaldo Arenas, apresenta três narradores (yo, tú, él - eu, tu, ele), que se alternam ao longo das peripécias de seu protagonista, o frei dominicano José Servando Teresa de Mier Noriega y Guerra (1763-1827). Tal procedimento narrativo revela-se de grande fecundidade para oferecer versões sobre os eventos históricos vivenciados pelo religioso mexicano, assim como acentua e humaniza esse personagem na narrativa.

A respeito dos diferentes narradores que se encontram no romance de Arenas, Germán Garrido (2008, p. 8) tece as seguintes ponderações:

Los saltos de narrador (de primera a segunda, de segunda a terceira, etcétera) en EMA [EI mundo alucinante] permiten en muchas ocasiones un desfasaje en el tempo que atenta contra la sucesión progresiva de los hechos. [...] La apuesta por la continua transmutación entre los narradores, [...] permite cuestionar la linearidade de esos acontecimentos, dinamizando aquel pasado, abriendo su ámbito a una intercención presente en la que el tempo de la historia se actualiza en el momento de sua narración. [...]

\footnotetext{
${ }^{1}$ Este texto é uma reelaboração de um subitem do capítulo terceiro de nossa tese de doutorado $A$ reescritura da história em El mundo alucinante, de Reinaldo Arenas, defendida na Universidade Estadual Paulista Júlio de Mesquita Filho - UNESP, Campus de Assis-SP, em 2004.

${ }^{2}$ Mestre e Doutor em Teoria Literária e Literatura Comparada pela Universidade Estadual Paulista Júlio de Mesquita Filho, Campus de Assis-SP, UNESP e professor do Mestrado em Letras e em Comunicação da Universidade de Marília-SP, UNIMAR. E-mail: abotoso@uol.com.br
} 
O romance de Arenas, por meio de três narradores, articula temporalidades distintas - presente e passado - apresentando versões plausíveis dos dados históricos e de frei Servando, abolindo as verdades totalizadoras para enfatizar que qualquer evento ou personalidade histórica merece ser encarada sob diversos e distintos pontos de vista, conforme deixam patente os narradores da obra em apreço.

Ao entramos em contato com o livro El mundo alucinante, verificamos que seu título já fornece uma chave interpretativa, pois remete à ideia de eventos extraordinários. Com a leitura, confirmamos que Servando Teresa de Mier é protagonista de grandes façanhas e que tudo em relação à sua vida parece tão inverossímil que o discurso histórico, enquanto ciência, que busca objetivamente narrar o ser histórico, assemelha-se a um enredo ficcional.

Todos os capítulos do livro têm um título que é uma espécie de síntese dos fatos neles narrados, à maneira da indicação de capítulos que encontramos nas convenções editoriais das crônicas coloniais, no romance picaresco e no Dom Quixote (1ª . parte 1605, 2a . parte - 1615), de Cervantes, por exemplo. A obra possui quarenta e dois capítulos e está dividida em doze partes, cada uma delas com o nome de um país, ou cidade, onde Mier viveu ou visitou. Inicia-se com o México (15 capítulos), depois Espanha (8 capítulos), França (4 capítulos), Itália (1 capítulo), Espanha (3 capítulos), Portugal (1 capítulo), Inglaterra (2 capítulos), Estados Unidos (1 capítulo), México (1 capítulo), Havana (1 capítulo), Estados Unidos (1 capítulo), e México (4 capítulos). O nome de alguns países repete-se, mas obedece, de maneira geral, à incessante locomoção histórica do frei dominicano, que a ficção procurou, dentro do possível, preservar.

O sumário do romance chama a atenção porque nele notamos que há três capítulos I, três capítulos II, três capítulos VII, e dois capítulos XXVII, como se verificar pelo seguinte esquema composicional:

Capítulo I. De cómo transcurre mi infancia en Monterrey junto con otras cosas que también transcurren

Capítulo I. De tu infancia en Monterrey, junto con otras cosas que también ocurren

Capítulo I. De cómo pasó su infancia en Monterrey, junto con otras cosas que también pasaron

Capítulo II. De mi salida de Monterrey

Capítulo II. De la salida de Monterrey

Capítulo II. De tu salida de Monterrey

Capítulo VII. De las consecuencias del sermón

Capítulo VII. De la consecuencia del sermón 
Capítulo VII. De la consecuencia del sermón

Capítulo XXVII. De las nuevas amistades del fraile y su escapada para América

Capítulo XXVII. De las nuevas amistades del fraile y su escapada para América (ARENAS, 1997, p. 8-9).

Cada um desses capítulos é narrado desde uma perspectiva diferente com a alternância entre três pontos de vista diferentes, estruturados na primeira, segunda e terceira pessoas discursivas. Esse recurso é, sem dúvida, um dos componentes do experimentalismo com a linguagem que referendam a construção pós-moderna do romance. A alternância de narradores acaba fragmentando e reinscrevendo permanentemente a imagem de Mier, razão pela qual só temos uma idéia e compreensão mais exata de sua figura ao final da obra.

O primeiro capítulo apresenta três versões em tensão de fatos ocorridos na infância do protagonista, isto é, um narrador em primeira pessoa e outros dois, em segunda e terceira. Na primeira versão, surge um narrador em primeira pessoa que relata os seguintes fatos:

Venimos del corojal. No venimos del corojal. Yo y las dos Josefas venimos del corojal. [...] En Monterrey todo se pasa así [...].

Allí estaba yo: descansando debajo de las espinas grandes. Descansando de la carrera y huida que le jugué al bebe chicha del maestro. (ARENAS, 1997, p. 27).

Esse primeiro fragmento apresenta um narrador em primeira pessoa que narra sua infância e uma suposta fuga aos castigos infligidos pelo mestre na escola. Algumas páginas mais adiante surge o narrador em segunda pessoa: "Ya vienes del corojal. El día entero te lo has pasado allí, debajo de las pocas hojas de las únicas matas que se dan por todo este lugar. [...] No fuiste a la escuela ni volviste al mediodía a la casa para almorzar" (ARENAS, 1997, p. 31).

O narrador ostenta um tom de recriminação a respeito das ações do menino Servando Teresa de Mier. Acusa-o de não haver feito nada durante o dia inteiro. Acrescenta ainda que ele não fora à escola e nem voltara para casa para almoçar. Depois deste narrador, aparece o narrador em terceira pessoa:

Así se pasaba el tiempo, y así pasó hasta descubrir que no existía y que sólo era una noción falsa con la cual empezamos a temerle a la muerte, [...]. Qué infancia tan corriente entre aquellas casas casi iguales. [...] De modo que no fue a la escuela ni siguió el rastro de la única garzota que había cruzado sobre las tejas. [...] Ni vio a sus hermanas, pues aún no habían nacido. [...] Inventos. Inventos... (ARENAS, 1997, p. 34). 
$\mathrm{Na}$ versão apresentada por este narrador, há alguns acréscimos em relação às versões anteriores, os quais confirmam a inércia do personagem, mas também o contestam, já que negam a presença das irmãs nesse momento específico da vida do protagonista.

O narrador em questão confirma a versão apresentada pelo narrador de segunda pessoa, que acusou o personagem de não haver feito nada durante um dia inteiro e também declara que Servando Teresa de Mier, como todas as crianças, é capaz de usar a imaginação livremente. Nos exemplos dados, notamos que todos os narradores apresentam-nos o menino de formas distintas e variadas. Há permanente construção e desconstrução e discursiva de forma que algumas informações são negadas e outras confirmadas. Contudo, importa ressaltar que cada narrador fornece uma imagem convincente do protagonista como uma criança rebelde, de imaginação fértil e que se recusou a ir à escola. Ao fazê-lo, refletem, em termos metalinguísticos sobre o aspecto de invenção inerente à própria narrativa.

Em relação aos narradores, convém observar que o primeiro participa dos acontecimentos narrados, assumindo o duplo papel de narrador e de personagem. Seu conhecimento é, geralmente, parcial e restringe-se à sua subjetividade, uma vez que ele só pode saber/informar sobre si mesmo ou sobre fatos dos quais participa ou observa como personagem.

O terceiro é um narrador que está fora dos acontecimentos narrados e relata fatos sem fazer nenhuma alusão a si mesmo como instância narrativa. Entretanto, não oferece uma visão mais objetiva dos fatos narrados em relação aos outros dois narradores (eu/tu). Diversamente do que ocorre na ficção tradicional, na qual o narrador em terceira pessoa é onisciente, sabe tudo a respeito do mundo romanesco e dos personagens que o povoam, no romance sobre Servando Teresa de Mier este fato não ocorre, o que neutraliza o conhecimento prévio do narrador onisciente e confere ao relato maior ambigüidade. Assim, com a utilização dos três narradores, como acertadamente constata Emil Volek (1985, p. 129), "tenemos ante nosotros [...] versiones y diversiones equivalentes, igualmente poco fiables, llenas de una imaginación paranoica, contradictoria; un texto que se repliega, paródicamente, sobre sí mismo". Deste modo, as versões contraditórias coexistem, reescrevendo permanentemente, com maior ou menor tensão, as ações em trânsito pelas diversas vozes. Tal procedimento estampa o caráter auto-reflexivo da 
narrativa, salienta seu teor de fabulação e explicita o componente subjetivo da visão histórica.

A narração em segunda pessoa "es más 'retórica', más enfática, y es más dramática por el diálogo que se establece entre el narrador y el personaje" (VOLEK, 1985, p. 134). Devido a sua especificidade, o narrador em segunda pessoa merece que nos detenhamos mais atentamente em sua conceituação. Trata-se de um recurso pouco utilizado pelos escritores e que não é muito discutido pelos críticos literários. Dentre os poucos teóricos que tratam desse assunto, destacam-se R. M. Albérès (1962), Manuel Baquero Goianes (1972), Leyla Perrone-Moisés (1966), Julia Kristeva (1974) e também Michel Butor (1974). Butor, além de escrever um romance empregando a segunda pessoa, produziu textos teóricos nos quais aborda os três tipos de narradores que podem estar presentes num romance. Sobre o narrador em primeira e terceira pessoas, o escritor francês tece as seguintes considerações:

Na leitura do mais simples episódio de um romance, há sempre três pessoas implicadas: o autor, o leitor, o herói. Este último toma geralmente a forma gramatical da terceira pessoa do verbo: é aquele de quem nos falam, cuja história nos contam.

Mas é fácil ver que vantagens pode haver para o autor em introduzir na obra um representante dele mesmo, aquele que nos conta sua própria história, dizendo-nos 'eu'.

O 'ele' nos deixa no exterior, o 'eu' nos faz entrar no interior, mas esse interior corre o risco de ser fechado [...]. Essa personagem não pode dizernos o que ela sabe de si mesma. (BUTOR, 1974, p. 81).

De acordo com Butor, o narrador em terceira pessoa conta os fatos que dizem respeito ao exterior do personagem. Já o narrador em primeira pessoa faz com que o leitor penetre no mundo interior do personagem. Contudo, há limitações no emprego deste último narrador, pois ele pode fechar-se tornando o seu interior indecifrável e obscuro para o leitor. Esse motivo, segundo Butor (1974, p. 81), justifica a opção por um narrador em segunda pessoa: "Eis por que se introduz por vezes na obra um representante do leitor, daquela segunda pessoa à qual o discurso do autor se dirige: aquele a quem se conta sua própria história."

A segunda pessoa, na concepção de Butor, representa o leitor. Portanto, esse recurso seria uma possibilidade de tornar o leitor mais atuante e participante em relação aos eventos narrados no romance.

O crítico francês R. M. Albérès (1962, p. 410) discute brevemente o narrador em segunda pessoa em seu livro Histoire du roman moderne. O referido crítico apresenta 
dois exemplos desse tipo de narrador. O primeiro é extraído do livro La modification (1957), de Michel Butor. Para Albérès, o romance de Butor identifica, pelo uso inesperado da segunda pessoa, leitor e herói do romance. Ainda, de acordo com as concepções de Albérès, a segunda pessoa no lugar do 'eu' ou 'ele' tradicionais visa modificar a ótica de leitura e permite, pela insistência, transformar um relato "exterior" em uma obsessão íntima. O segundo exemplo baseia-se no conto de ficção-científica do escritor norteamericano Théodore Sturgeon (1918-1985), intitulado "L'homme qui a perdu la mer". Conforme Albérès (1962, p. 410-411), os dois escritores, Sturgeon e Butor, apelam para um mesmo procedimento narrativo porque o propósito de ambos é semelhante, o de sugerir uma experiência humana apresentada como algo extraordinário ou como um enigma e "l'aborder par um autre biais que celui de la narration, en faire non pas un récit aisé, mais un mystére, un objet inquiétant qui fixe et qui fascine la curiosité". 3 Poeticamente, o procedimento mencionado reveste-se grandes potencialidades quando utilizado na estruturação de um relato.

O emprego do narrador em segunda pessoa revela-se uma estratégia eficaz para dotar a narrativa de mistério e efeito de profundidade, para variar as perspectivas sob as quais um mesmo fato pode ser visto dentro da trama romanesca.

Depois de Butor, de acordo com as considerações de Manuel Baquero Goianes (1972, p. 127), também utilizaram a segunda pessoa em suas obras Georges Perec (1936-1982), em Un homme qui dort (1967) e, entre os autores ingleses, Peter Everett, em The fetch (1969). Mas, ainda de acordo com Baquero Goianes (1972, p. 128), o romance de Butor, mencionado anteriormente, consagrou a estrutura narrativa em segunda pessoa e seu uso poderia diminuir ou até mesmo eliminar a suposta a passividade do leitor de romances, porque este se converte no protagonista "al que le está sucediendo cuanto se presenta em la novela, se da entonces una - por supuesto, momentánea, ilusoria - desaparición de tal pasividad, sustituida por el máximo implicamiento: el de esa transmutación protagónica". O leitor, dessa forma, passa a "viver diretamente" a experiência do protagonista como se fosse a sua própria.

A ensaísta e crítica literária paulista Leyla Perrone-Moisés, também analisa o narrador em segunda pessoa de Butor, ponderando que o emprego da instância narrativa

\footnotetext{
3 "[...] abordá-la por um outro viés que aquele da narração, fazendo não um relato acomodado, mas um mistério, um objeto inquietante que fixa e fascina a curiosidade" (ALBÉRÈS, 1962, p. 410-411, tradução nossa).
} 
mencionada é inovadora, além do fato de seu livro La modification (1957) apresentar novidades na disposição tipográfica e ser bem construído. Julia Kristeva, por sua vez, atesta que no romance polifônico há várias possibilidades para o emprego de narradores: narração em terceira pessoa (ele), a técnica narrativa mais simples e que se encontra no nascimento da narrativa; a coincidência do sujeito do enunciado com o sujeito da enunciação, a narração em primeira pessoa (eu). Além dessas, quando ocorre "a coincidência do sujeito do enunciado (Se) com o destinatário (D)", assinala Kristeva a existência da narrativa em segunda pessoa.

Como se nota, nos textos teóricos que tratam da narrativa em segunda pessoa, o exemplo citado é o mesmo, o romance do escritor francês Michel Butor, fato que comprova que o número de romances que emprega esse tipo de narrador é bastante reduzido. Portanto, destacamos que não há muitos escritores que utilizam esse recurso, mas, a título de exemplificação, convém assinalar que nas literaturas espanhola e hispano-americana localizamos, respectivamente, as seguintes obras: Reivindicación del conde don Julián (1970), de Juan Goytisolo, e La muerte de Artemio Cruz (1962), de Carlos Fuentes, que empregam simultaneamente as três pessoas discursivas.

Com a utilização de um narrador na segunda pessoa é fato que

o romancista engaja o leitor diretamente na narrativa, pois cada um se sente implicado de modo pessoal. Ao mesmo tempo, o 'vous' dá à personagem um caráter universal e ele passa a ser não um homem em particular mas o homem com seus problemas eternos. (PERRONEMOISÉS, 1966, p. 41).

O emprego do narrador em segunda pessoa, conforme argumenta Perrone-Moisés, confere ao personagem um caráter de universalidade na representação da condição humana. Entre a narração em primeira e em terceira pessoa, a segunda representa um meio-termo, um equilíbrio entre as outras vozes, ainda de acordo com a autora:

Jean Pouillon em Temps et roman [...] afirma que o romancista está sempre 'com' a personagem (quando emprega a primeira pessoa) ou 'atrás' da personagem (quando emprega a terceira). Butor consegue, ao empregar a segunda pessoa, uma posição intermediária: o romancista está 'com' a personagem - já que o 'vous' subtende um 'je' que a ele se dirige e ao mesmo tempo fora dela, como o romancista demiurgo, cujo protótipo é Balzac. (PERRONE-MOISÉS, 1966, p. 41-43).

Tal narrador institui um diálogo com o personagem e também assume uma posição "demiúrgica", pois revela conhecer e saber com certa profundidade a maioria dos fatos e 
ações praticados pelo personagem tanto quanto qualquer narrador onisciente dos romances realistas do século XIX.

O único estudo sobre o narrador em segunda pessoa realizado no Brasil de que temos notícia é a dissertação de mestrado de Camila Chaves Cardoso (2007), que se intitula As imagens duplas e a narração em segunda pessoa em Aura, obra fantástica de Carlos Fuentes. Nessa pesquisa, a autora põe em relevo o narrador em segunda pessoa na obra Aura (1962), do escritor mexicano Carlos Fuentes (1928 - 2012). Ao caracterizar esse tipo de narrador, Camila Cardoso (2007, p. 115) enfatiza que a

narração em segunda pessoa, além de retomar a tradição [...] de levar à identificação entre leitor e personagem, intensifica-a, na medida em que é a primeira instância da obra a provocar um processo de duplicação no âmbito da instância da leitura. Pondo em xeque a identidade do leitor, gera oscilação, hesitação, mistério e ambiguidade. [...]

Além disso, ainda segundo a referida estudiosa,

O procedimento termina por convocar o leitor a desempenhar um papel mais ativo no relato, uma vez que sua figura está gramaticalmente marcada no corpo do texto, enredado, em todos os sentidos do termo, pelos pronomes e desinências verbais que marcam a segunda pessoa do singular. (CARDOSO, 2007, p. 1).

Camila Cardoso considera como elementos preponderantes na narrativa em segunda pessoa o fato de haver uma identidade entre leitor e personagem e também porque esse procedimento é um convite para que o leitor passe a exercer um papel ativo dentro do relato, conforme já apontaram outros estudiosos que mencionamos anteriormente.

É válido acrescentar que o narrador em segunda pessoa conjuga dois posicionamentos, o de aproximação e afastamento em relação aos fatos narrados, o que permite variações significativas nos significados que a obra projeta. No fragmento do romance que transcrevemos anteriormente e que apresenta um narrador em segunda pessoa, fica claro um certo grau de reprovação, dirigido ao personagem, pelo emprego de advérbios de negação - não/nem: "No fuiste a la escuela", "ni volviste al mediodía" (ARENAS, 1997, p. 31). Esse narrador, de certa forma, apresenta uma versão bem diferente daquela que foi exposta pelo narrador em primeira pessoa, contradizendo-o.

O emprego dessa forma narrativa dá um caráter moralista ao relato: "No fuiste a la escuela ni volviste al mediodía [...]/ Mejor será que pienses en otra cosa" (ARENAS, 1997, 
p. 31-33). O tom moralista vem expresso pela censura e também pelo conselho dado ao personagem para que pense em outra coisa. A este propósito, observa-se que a segunda pessoa foi também utilizada por La Fontaine em algumas fábulas, com o valor didático de pregar uma moral da história narrada, e pode ainda ter "um valor acusatório ou elucidativo, como se a personagem se recusasse a contar ela própria o acontecido" (PERRONE-MOISÉS, 1966, p. 42-43).

Vale ressaltar que o narrador em segunda pessoa dialoga com o personagem e oferece sempre um contraponto em relação às versões apresentadas pelos narradores em primeira e terceira pessoas. Consideramos que o prefácio "inaugura" a narração em segunda pessoa quando se estabelece o diálogo entre Reinaldo Arenas e o tu de Mier, como já observamos anteriormente.

No romance de Arenas, o emprego do narrador em segunda pessoa cumpre, geralmente, uma função "acusatória" com relação às ações do frei e também "elucidativa", porque esclarece ou nega informações prestadas pelos demais narradores, como podemos notar na tensão discursiva que se estabelece entre três segmentos da obra, extraídos dos capítulos III, VII e XVIII, respectivamente:

Llegaste ya de noche, pues no te cansaste de merodear por todo el pueblo y de ponerle faltas a todo. ¡Tan joven y tan protestón! ¡Tan joven y siempre poniendo reparos! Criticando este lugar donde nuestros angelitos arrullan muy quietos. ¡Ah, so gruñón!, corriendo fuiste a ver al padre Terencio, [...]. Y tú, pedazo de bestia, lo rechazaste, [...]. (ARENAS, 1997, p. 48).

Dos meses van que estás en esa celda. Preso. Que bien te lo mereces por provocar la ira de tus superiores. (ARENAS, 1997, p. 69).

Jamás has estado en Madrid. Jamás has atravesado los Pirineos. Ni has pasado por todos esos lugares que mencionas y criticas. (ARENAS, 1997, p. 161).

Além dos advérbios de negação "no", “jamás”, "ni”, as críticas e acusações do narrador vêm expressas por meio de frases exclamativas e também por adjetivos e locuções como "protestón”, "gruñón”, "pedazo de bestia”, que caracterizam negativamente as atitudes do frei. De acordo com o narrador em segunda pessoa, Servando é um personagem que só sabe fazer críticas e não é capaz de enxergar nenhuma atitude positiva, seja na igreja ou nos países pelos quais é obrigado a transitar na condição de exilado. Cabe também acrescentar que o uso da segunda pessoa, além das particularidades por nós apontadas, revela o jogo de espelhos que não só permite a 
fragmentação do "eu" narrador, mas também corrobora a identificação do "eu" autoral com o protagonista do romance, identificação estabelecida, como vimos, no prefácio.

Não é só nos capítulos mencionados (I, II, VII e XXVII) que os narradores se alternam. Em quase todos os capítulos do livro esse procedimento é mantido. A título de esclarecimento, vejamos alguns fragmentos do capítulo IX:

Cayendo el día lo llevaron hasta el buque 'La Nueva Empresa'. Lo hicieron descender por escaleras sin escalones, y en el último fondo del barco lo tiraron en una bartolina peor que la de San Juan de Ulúa, [...].

Sin otra dificultad, a no ser la muerte del capitán de 'La Nueva Empresa', [...] el barco seguirá su travesía hasta llegar a las costas de Europa. (ARENAS, 1997, p. 76-77).

No capítulo citado, Servando Teresa de Mier é transportado da prisão de Veracruz para outra, em Cádiz. Segundo essa primeira versão do narrador onisciente, nada de extraordinário aconteceu, com exceção da morte do capitão. Já o narrador-personagem conta que a viagem tornou-se problemática, pois

fui llevado hasta el horrible buque 'La Nueva Empresa', que de tan viejo que estaba chorreaba agua por los cuatro costados [...].

Y, sin remedio, fui lanzado por la borda. [...]. Y un momento después vi la nave estremecerse de un golpe y hundirse sin escapatoria en el mismo horizonte. (ARENAS, 1997, p. 77-82).

A narração em primeira pessoa permite uma maior proximidade do leitor em relação às ações narradas, além de desvelar o caráter confessional da instância narrativa, que revive momentos turbulentos da viagem. O navio, velho e em estado precário, afunda. O narrador em segunda pessoa fala de uma viagem desastrosa, pois o navio fora atacado por centenas de tormentas. Mier é obrigado a terminar a viagem a nado, como se observa:

Y saliste a bordo de 'La Nueva Empresa' del puerto de Veracruz.

Desterrado...

Y fue el barco atacado por centenares de tormentas de todas magnitudes. $[\ldots]$

A nado llegaste a las costas de Cádiz -la blanca-. Tan flaco, tan hambriento, que no pudiste más que caer sobre la arena y empezar a dormir... Todas las olas llegaban hasta tus pies. Y te los mojaban. $Y$ te los volvían a mojar. (ARENAS, 1997, p. 83-85).

Outros acréscimos vão se juntando à versão apresentada pelo narrador em primeira pessoa. A narrativa em segunda pessoa amplia as ações narradas anteriormente, redimensionando e ampliando hiperbolicamente o naufrágio. 
As passagens acima tratam da viagem de Servando Teresa de Mier no navio 'La Nueva Empresa', do México para a Espanha. Ele está preso e vai ser conduzido para o cárcere de Las Caldas, em Cádiz. Cada um dos narradores apresenta uma versão da viagem. Para o narrador onisciente, o trânsito, apesar dos pequenos contratempos, transcorre normalmente. Já o narrador/personagem informa que foi jogado do navio e que este, pouco depois, afundou. O narrador em segunda pessoa declara que o navio, vitimado por inúmeros acidentes, afundou e que Mier chegou a Cádiz nadando.

Este procedimento de mistura de pontos de vista é conhecido como visão estereoscópica, segundo Tacca (1983, p. 89). Essa é uma visão plural ou 'prismática', da qual "nasce um novo modo de conhecimento romanesco, soma de conhecimentos parciais - raramente coincidentes, frequentemente dissidentes e até contraditórios - de grande riqueza e interesse para uma compreensão mais profunda do drama" do personagem, que permite ao leitor diferentes interpretações e instaura o universo romanesco como uma soma de possibilidades.

O escritor Willian Faulkner também empregou essa técnica em seus romances. Ele procurava contar o mesmo fato repetidas vezes através de vários enfoques. Como se pode constatar, trata-se de um recurso muito rentável para a ficção, pois as obras que o utilizam exibem maior teor de polifonia no relato das ações do romance

para que não sejam tomadas como verdades absolutas; fazem-no para que o leitor seja estimulado a refletir sobre as maneiras parciais, particulares, pelas quais elas construíram a realidade, desta forma reconhecendo que tudo aquilo poderia ter acontecido de maneira diferente. (EAGLETON, 1983, p. 183).

Em suma, a técnica referida acaba com a suposta objetividade da narrativa, debilitando-a e impondo, segundo Tacca (1983, p. 91) "uma tensão psicológica ao leitor, que tem que valorizar o acontecimento. O resultado é que o leitor se concentra, não na cena propriamente dita, mas nos modos de a ver". Esse procedimento narrativo apresenta um caráter metalinguístico, pois enfatiza as várias possibilidades de visão de um mesmo acontecimento, segundo o lugar a partir do qual é enunciado. Seu enfoque geralmente é a confirmação ou negação de um mesmo fato dentro da história narrada.

No capítulo XVI, Mier chega a Pamplona e encontra o seu perseguidor, Francisco Antonio León. Então, para fugir dele, é obrigado a mergulhar nas águas fétidas do fosso que cerca a cidade. Nesse capítulo, os três narradores alternam-se constantemente e, 
algumas vezes, tal alternância ocorre num mesmo fragmento, tal como se verifica nos trechos seguintes:

Yo estoy en Pamplona y el agua asquerosa se ribetea como un espejo aceitado que va lamiendo muy despacio las murallas. [...] $Y$ de esta manera volviste a transformarte en el antiguo fraile. $Y$ saliste muy orondo en cuanto escuchaste el levantamiento de los puentes. $Y$ comenzaste otra vez a pasearte por las calles.

Y así sucedió que paseándose por cerca de la muralla fue descubierto nuestro fraile por el malvado León (hombre infatigable). $Y$ he aquí que toda su cuadrilla de alguaciles te persigue [...].Y he aquí que huyes por toda la calle y un nuevo escuadrón te sale al paso. [...]

$Y$ mezclado en ella (agua intranquila) estuviste, oh fraile, flotando durante todo el día entre ese fangal que aísla la ciudad; [...].Y así fue que, sin que los atacantes lograran dar en el blanco, el fraile nadó (siempre por debajo del agua) hasta el pasadizo mayor, y se aferró a las cadenas del puente. (ARENAS, 1997, p. 148-150).

A viagem a Pamplona é dificultada pelo inimigo e perseguidor de Mier, o temível León, segundo nos informa o narrador em terceira pessoa. Os verbos e locuções empregados - "estoy", "volviste”, "huyes", "fue descubierto", "estuviste flotando", "nadó", "aferró" - somados às formas pronominais "yo", "te", "se" fazem variar as perspectivas narrativas, às vezes num único parágrafo. No entanto, nos fragmentos acima, assim como em vários momentos do relato, constatamos que os três narradores, ao invés de registrarem versões conflitantes de uma mesma cena, agora expressam ações semelhantes. A colaboração entre os narradores produz um efeito estilístico de grande rendimento para a narrativa porque os eventos ocorridos ganham mais vivacidade, pela intercorrência de perspectivas que reforçam a imagem de alucinação que vem expressa no título do livro.

Ainda que todo o capítulo XVI apresente uma uniformidade narrativa (os fatos e as cenas não são questionados ou desmentidos), no capítulo seguinte, o narrador/personagem faz a seguinte observação:

Antes de la madrugada pude escabullirme de las manos de León y dejar la villa de Madrid. Así me interné en Agreda y luego salí por Cataluña, que mis amigos habían dejado sin requisitoria. Allí pude ponerme en contacto con mis clérigos contrabandistas, que, repartiendo pesetas a todos los guardias, lograron salir conmigo y con toda su mercancía sin ninguna dificultad. Y muy cerca de Pamplona (ciudad que nunca he visitado, aunque muchos afirman que sí) mis comerciantes franceses hicieron llamar a un arriero que había llevado muchos clérigos a Francia por encima de los pirineos. (ARENAS, 1997, p. 152). 
O narrador em primeira pessoa afirma que nunca esteve em Pamplona, que apenas passou perto dessa cidade. De acordo com esse narrador, a visita a Pamplona é uma falácia engendrada por terceiros, carecendo, assim, de veracidade. Dessa maneira, o narrador desestabiliza a narrativa, desconstrói as asserções, deixando ao leitor a decisão sobre qual caminho o frei seguiu, se esteve em Pamplona ou não. Também há uma terceira opção, a de mais fértil rendimento poético, que é a instauração da dúvida. Se os narradores não se preocuparam em dissipá-la, o que deve nortear o leitor é que o romance trabalha com hipóteses, como declara Arenas no prefácio. Portanto, a incerteza e a dúvida são também campos fecundos que o romance de Arenas explora com muita acuidade. Seu romance joga com duas possibilidades, realidade/alucinação, que permeiam todo o relato e culminam no penúltimo capítulo entre os delírios e os momentos de lucidez de Mier, no palácio presidencial onde está residindo. A obra não representa uma "realidade absoluta", mas várias "realidades possíveis" e conflitantes.

Durante a leitura de El mundo alucinante, o leitor depara-se com variações focais que the permitem ter acesso aos acontecimentos de forma parcial e variada. Afinal, o modo pelo qual cada voz narra um fato tanto é divergente quanto convergente, além de muito diferente e subjetivo, o que nos obriga a entender, de acordo com Tacca (1983, p. 92), que

juntamente com a convicção de que só se chega à verdade através da multiplicação dos enfoques, existe outra, muito mais cética, de que não há verdade, mas verdades, ou, em todo caso, de que o conhecimento da verdade, na esfera do humano, é inalcançável.

No romance as versões, ao invés de se excluírem, somam-se na coexistência simultânea. Não há uma "realidade" ou versão hegemônica, mas um jogo de visões caleidoscópicas segundo as quais o relato, construído por três narradores, converte-se num jogo de espelhos, cujos fragmentos se contradizem e se complementam, desestabilizando o horizonte de expectativas do leitor.

São, portanto, possibilidades de verdades que o romance de Arenas expressa, valendo-se de inúmeros expedientes para recriar a figura histórica. O uso de três narradores revela-se eficaz recurso para a construção de uma visão plural, polivalente e, algumas vezes, até ambígua de Mier. Assim, a dinâmica que aciona o discurso brinda ao leitor um papel mais ativo no tocante à interpretação da trajetória histórica do frei dominicano. 
No romance El mundo alucinante, com o emprego de três vozes narrativas - yo, tú, él - ocorre a fragmentação discursiva, fato que evidencia que a referida obra faz parte daquilo que os teóricos e críticos consideram como pós-modernismo e, além disso, essas três vozes impõem uma tensão constante que dinamiza o universo poético ao não privilegiar uma única voz narrativa, a fim de pôr em destaque a polifonia do romance, revelando convergências e divergências na construção ficcional do frei mexicano José Servando Teresa de Mier Noriega y Guerra.

A pluralidade de vozes narrativas também exige um leitor atuante e participante dentro do tecido narrativo para decifrar e interpretar os acontecimentos narrados e, conforme apregoa Machado de Assis (1987, p. 127) em seu romance Esaú e Jacó, tal leitor deve ler o texto com os olhos de um leitor ruminante, o qual, só depois de refletir muito sobre o que foi lido e "digerido" pelo cérebro, é que deve tirar suas conclusões.

Portanto, a escolha de três narradores, que se alternam constantemente, e expõem pontos de vista conflitantes sobre um mesmo fato serve como alerta para que o leitor se conscientize de que o romance trabalha com versões que a história apresentou do frei e dos fatos que ele vivenciou em sua conturbada vida, passando por vários países, prisões e batalhas.

Enfim, a vida do frei mexicano foi realmente uma vida "alucinante" da qual os narradores em primeira, segunda e terceira pessoas podem somente dar versões plausíveis que permitem ao leitor aproximar-se e tirar suas próprias conclusões sobre uma das figuras mais apaixonantes e intrigantes da história da América Latina.

\section{REFERÊNCIAS}

ASSIS, Machado de. Esaú e Jacó. 4. ed. São Paulo: Cultrix, 1987.

ARENAS, Reinaldo. El mundo alucinante. Una novela de aventuras. 2. ed., Barcelona: Tusquets Editores, 1997.

ALBÉRÈS, R. -M. Histoire du roman moderne. Paris: Albin Michel, 1962.

BAQUERO GOYANES, Manuel. Personas, modos y tiempos en la estructura novelesca. In: BAQUERO GOYANES, Manuel. Estructuras de la novela actual. 2. ed., Barcelona: Editorial Planeta S. A., 1973, p. 121-133.

BOTOSO, Altamir. A reescritura da história em El mundo alucinante, de Reinaldo Arenas. Doutorado (Teoria Literária e Literatura Comparada). Universidade Estadual Júlio de Mesquita Filho, UNESP, Campus de Assis-SP, 2004. 
BUTOR, Michel. Repertório. Tradução e organização de Leyla Perrone-Moisés. São Paulo: Perspectiva, 1974.

BUTOR, Michel. La modification. Paris: Les Éditions de Minuit, 1957.

CARDOSO, Camila Chaves. As imagens duplas e a narração em segunda pessoa em Aura, obra fantástica de Carlos Fuentes. Dissertação (Mestrado em Teoria e História Literária). Instituto de Estudos da Linguagem, Universidade Estadual de Campinas, 2007.

EAGLETON, Terry. Teoria da literatura: uma introdução. Tradução de Waltensir Dutra. São Paulo: Martins Fontes, 1983.

ETTE, Ottmar (ed.). La escritura de la memoria: Reinaldo Arenas: textos, estudios y documentación. 2. ed., Frankfurt am Main: Vervuert; Madrid: Iberoamericana, 1996.

GARRIDO, Germán. La historia y sus voces en El mundo alucinante de Reinaldo Arenas. Cuarto Próprio. Revista literária. N. 4, mayo 2008, p. 1-11. Disponível em: http://cuartopropio.upra.edu/vol4/Articulo German Garrido.pdf. Acesso em 05/05/2012.

KRISTEVA, Julia. A palavra, o diálogo e o romance. In: KRISTEVA, Julia. Introdução à semanálise. Tradução de Lúcia Helena França Ferraz. São Paulo: Perspectiva, 1974, p. 61-90.

MIER, Fray Servando Teresa de. Ideario político. Prólogo, notas y cronología de Edmundo O'Gorman. Caracas: Biblioteca Ayacucho, 1978, v. 43.

PERRONE-MOISÉS, Leyla. O novo romance francês. São Paulo: São Paulo Editora S. A., 1966.

TACCA, Oscar. As vozes do romance. Trad. Margarida Coutinho Gouveia. 2. ed., Coimbra: Almedina, 1983.

VOLEK, Emil. La carnavalización y la alegoria en 'El mundo Alucinante', de Reinaldo Arenas. Revista Iberoamericana. Pittsburgh, (130-131): 125-148, 1985, vol. LI. 